\title{
Toward 1.8 Tb/s CAP Schemes for Short Reach Optical Communication Systems
}

\author{
${ }^{1}$ Majidah H. Majeed and ${ }^{2}$ Raad S. Fyath \\ ${ }^{1}$ Department of Electrical Engineering, College of Engineering, University of Baghdad, Baghdad, Iraq, \\ ${ }^{2}$ Department of Computer Engineering, College of Engineering, University of Al-Nahrain, Baghdad, Iraq \\ majidahmajeed@gmail.com; rsfyath@yahoo.com
}

\begin{abstract}
Wavelength-division multiplexed (WDM)carrierless amplitude/phase (CAP) modulation is proposed for 1.8 $\mathrm{Tb} /$ sfor short reach optical communication system. The system uses 16 channels, each operates at 112 $\mathrm{Gb} / \mathrm{s}$. A single-band (SB) CAP and multiband (MB) CAP are adopted for each channel as advanced modulation format with high spectral efficiency. The system performance at $\mathrm{C}$ and $\mathrm{O}$ operating bandsare investigated withchannel spacing of $100 \mathrm{GHz}$.The system is simulated using OptiSystem 14.0 software package and the results reveal that the maximum allowable distance at BER of $\llbracket 10 \rrbracket \wedge(-3)$ is $3.45 \mathrm{~km}$ and $2.11 \mathrm{~km}$ for SB-CAP and MB-CAP operating at C-band with $0 \mathrm{~dB}$ laser power, respectively. These values to be compared with $4.5 \mathrm{~km}$ and $1.8 \mathrm{~km}$, respectively, for O-band operation.
\end{abstract}

Keywords: Multiband CAP, single-band CAP, WDM-CAP

\section{Introduction}

The increasing cloud computing and multimedia services has driven the speed of short reach optical data communication links to higher data rate. In fact, $100 \mathrm{Gbit} / \mathrm{s}$ bit rate has been addressed comprehensively for this application [1-4] while discussion has been actively started for $400 \mathrm{Gbit} / \mathrm{s}$ and above data links [56]. To reduce the cost of the optical data link, directly modulated lasers with direct detection (DD) schemes have been adopted [7-10]. To increase the spectral efficiency of these links, higher-order modulations formats have been proposed [11,12]. Recently, different direct detection schemes have been investigated for advanced short reach applications such as orthogonal frequency-division multiplexing (OFDM) $[13,14]$, multitone (DMT) modulation [15,16], Pulse amplitude modulation (PAM) [17-19], and CAPmodulation [20,22].

The CAP modulation attracts increasing interest as an efficient modulation format for short reach optical communication. In fact CAP implementation is relatively simple since it uses analogue transversal filters and does not need digital signal processing (DSP) [23]. This gives the potential of both improved cost and energy efficiency while also having excellent performance. These features have enhanced the researches to investigate single- band CAP (SB-CAP), multiband CAP (MB-CAP), and hybrid CAP/QAM schemes. Tao et al. $[24,25]$ investigated the performance of $40 \mathrm{~Gb} / \mathrm{s}$ SB-CAP32 and 10Gb/s SB-CAP128/256 systems with decision-directed least mean square (DD-LMS) adaptive equalization algorithm for short-reach optical transmissions. An overlap frequency-domain equalization (OFDE)scheme proposed and 
Majidah H. Majeed and Raad S. Fyath; Toward $1.8 \mathrm{~Tb} / \mathrm{s}$ CAP Schemes for Short Reach Optical Communication Systems, Transactions on Networks and Communications, Volume 5 No. 1, February (2017); pp: 39-52

experimentally demonstrated by He et al. [26] in an intensity modulation and direct detection optical communication system with SB-CAP32/64/128 modulation. Zhang et al. [27] proposed and demonstrate a wavelength-division multiplexed(WDM) MB-CAP with direct detection. The experiment successfully demonstrates 11 WDM channels, 55 subbands, for 55 users with 9.3-Gb/s per user in the downstream over 40-km single mode fiber (SMF). Recently, A $100 \mathrm{~Gb} / \mathrm{s}$ MB-CAP was successfully demonstrated over $15 \mathrm{~km}$ SMF by Olmedo et al. [28]. Their results show an increases tolerance towards dispersion and bandwidth limitations, and reduces the complexity of the transceiver. Unfortunately, CAP receivers have relatively low tolerance to high frequency jitter and therefore desirable to propose an alternative approach with simple implementations.

Recently, a hybrid CAP/quadrature amplitude modulation (QAM) transmitter/receiver scheme was proposed to be used instead of a conventional non phase compensated CAP transceiver to improve both the system jitter tolerance and optical link power margin. An experimental demonstrations of a $10 \mathrm{~Gb} / \mathrm{s}$ hybrid SB-CAP-2/QAM-2 and a $20 \mathrm{~Gb} / \mathrm{s}$ hybrid SB-CAP-4/QAM-4 transmitter/receiver-based optical data link were performed by Wei et al. [29]. The work was extended to MB-CAP system by the same research group [23].

It is clear from the forging survey that the performance investigation of CAP system is limited to a maximum bit rate of $100 \mathrm{~Gb} / \mathrm{s}$. To the best of authors knowledge, the performance of CAP system for bit rate beyond $100 \mathrm{~Gb} / \mathrm{s}$ has not addressed in the literature. This paper presents performance investigation for a1.8Tb/s WDM-CAP system. The system uses 16 x112Gb/s CAP/QAM channels operating either in single band or multiband formats. Results will be reported for both C-band and O-band operating regions.

The remainder of the paper is organized as follows: Section two demonstrates the architecture of proposed WDM single-band and multiband CAP-16 systems. The simulation setup and the results are presented in Section 3 which discusses the performance of the system at channel-spacing $100 \mathrm{GHz}$. The conclusions deduced from this work are presented in Section 4.

\section{Proposed 1.8 Tb/s WDM-CAP System}

The architecture of the proposed $1.8 \mathrm{~Tb} / \mathrm{s}$ WDM-CAP system is illustrated in Figure 1 . The sixteen $112 \mathrm{~Gb} / \mathrm{sWDM}$ channels operating either atC-bandor O-band. The transmitter and receiver use either single-band CAP (SB-CAP)or MB-CAP modulation format. Each channel uses a CAP-M signal (M is the modulation order where $M=16$ is applied here). This is similar to QAM-M signaling, however, it neither needs RF local oscillator nor mixer. Figure 2 shows the schematic diagram of the transmitter and the receiver for WDM CAP system. ThePAM mapper is used to map the binary datainto the orthogonal inphase (I) and quadrature (Q) components of complex symbols. The RF CAP signal is created by combining the outputs of two orthogonal filters that are called Hilbert pair. The MB-CAP designed with four subbands $(\mathrm{K}=4)$ requires four orthogonal filter pairs having different center frequencies to prevent the overlapping between two adjacentsubbands. Each of the sixteen channel signals modulates single continuous wave (CW)optical carrier using intensity modulatorMach-Zenhder (MZM) modulator. Thesixteen signals arewavelength-division multiplexed to propagate simultaneously through SMF.At the receiver side, direct detection is applied to the received de-multiplexed signal followed by QAM demodulator for each channel. The two matched filters used here will separate the I and Q components; these filters are of complex conjugate of the shaping filters in the frequency domain. The signals at thefilters outputare off-line processed using digital signal processing (DSP) then the decision is made using 
decision device to get the real and imaginary components that are decoded by QAM decoder to get the original data.

The MB-CAP modulation utilizes multi-filter pairs located at different center frequencies $\square \mathrm{f} \rrbracket \_(k, c)$. For each sub-band, two transversal filters are generated by time multiplication the impulse response of square root-raised cosine (SRRC) shaping filter with a sine or cosine waveform. The center frequencies of the kthsubbandpair transversal filters is given by equation 1

$$
\mathrm{f}_{\mathrm{k}, \mathrm{c}}=\frac{1}{2 \mathrm{~T}}(1+r)(2 \mathrm{k}-1) \quad \mathrm{k}=1,2,3, \ldots \mathrm{K}
$$

where $T$ is the symbol period, $r$ is the roll-off of the SRRC filter and is set to 0.2 here, $K$ is the total number of subbands. The SB-CAP format can be considered as a special case of MB-CAP with number of subbands equals one.
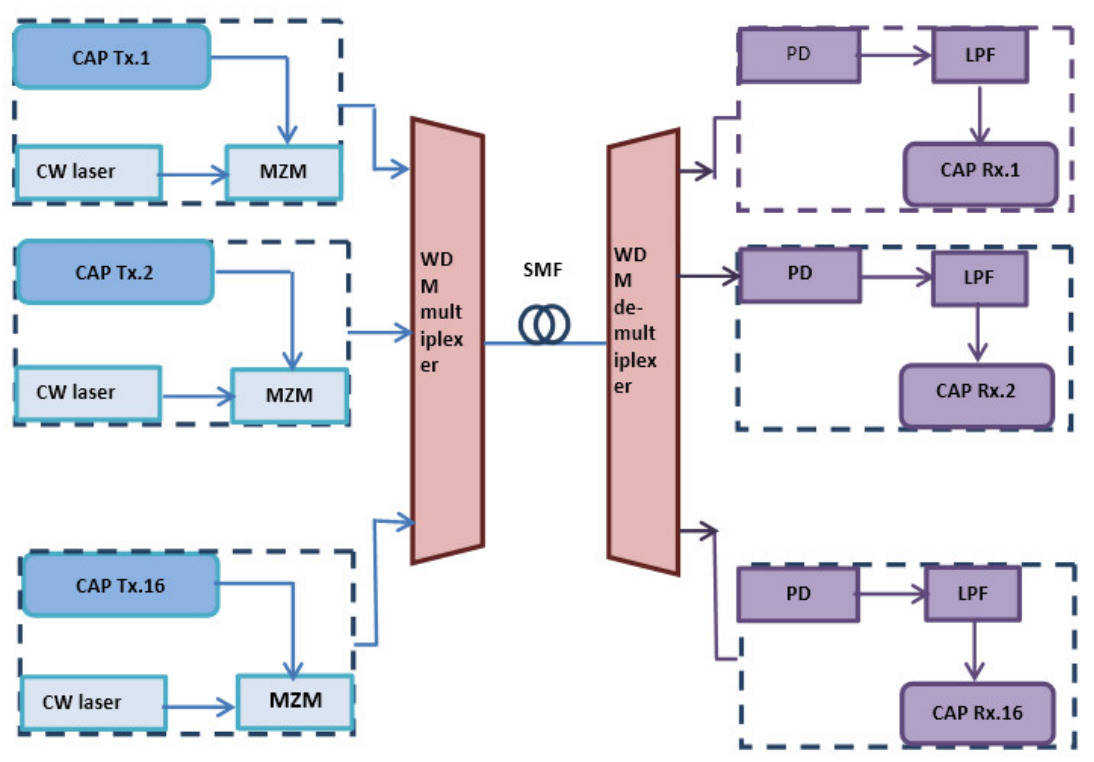

Figure. 1 Architecture of WDM CAP system. The CAP transmitter (CAP-Tx) and CAP receiver (CAP-Rx) can be implemented using single-band or multiband CAP schems.

The impulse response of the orthogonal SRRC shaping filters is given by

$$
\begin{aligned}
& R_{k, c}(t)=g(t) \cos \left(2 \pi f_{k, c} t\right) \\
& \overline{R_{k, c}}(t)=g(t) \sin \left(2 \pi f_{k, c} t\right)
\end{aligned}
$$




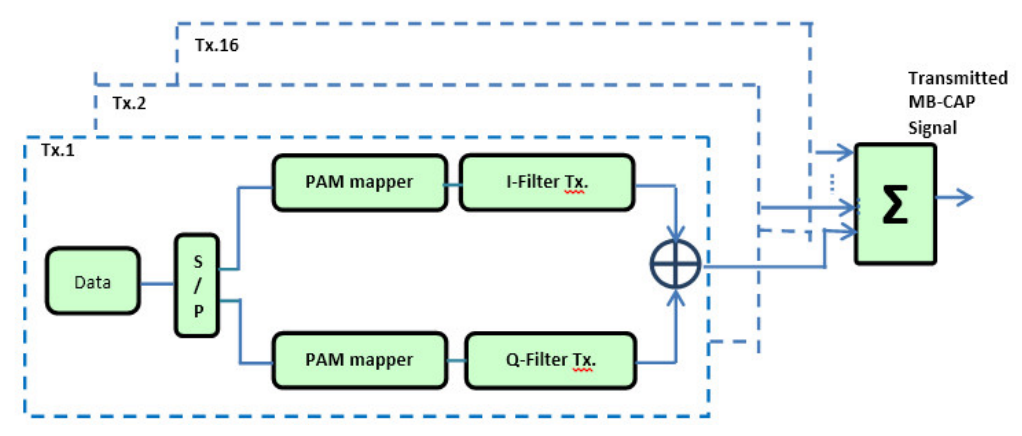

(a)

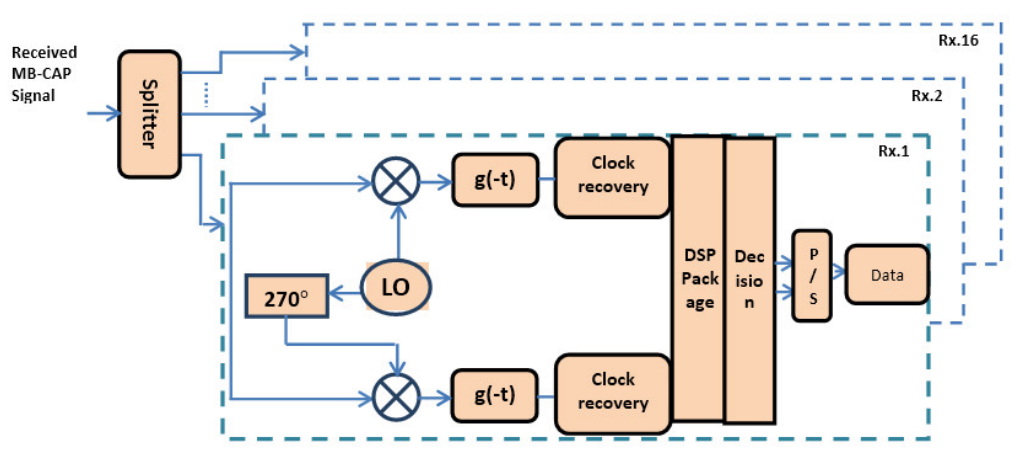

(b)

Figure.2Schematic diagram of MB-CAP system (a) transmitter. (b) receiver.

where $\mathrm{g}(\mathrm{t})$ is the impulse response of SRRC filter of and $f_{k, c}$ is the center frequency of $\mathrm{k}^{\mathrm{th}}$ subband The MB-CAP signal can be expressed by

$$
\mathrm{S}(\mathrm{t})=\sum_{k=1}^{K}\left\{\sum_{i} X_{k, i} g(t-i T) \cos \left[\omega_{k, c}(t-i T)\right]-\sum_{i} Z_{k, i} g(t-i T) \sin \left[\omega_{k, c}(t-i T)\right]\right\}
$$

where $X_{k, i}$ and $Z_{k, i}$ are the I and Q parts of the ${ }^{\text {th }}$ subbandPAM-M symbols, and $\omega_{k, c}=2 \pi \mathrm{f}_{k, c}$.

At the receiver, the orthogonal matched filters having the following impulse responses

$$
\begin{aligned}
& U_{k, c}(t)=g(-t) \cos \left(2 \pi f_{k, c} t\right) \\
& \overline{U_{k, c}}(t)=g(-t) \sin \left(2 \pi f_{k, c} t\right)
\end{aligned}
$$

\section{Simulation Setup and Results}

The investigation of $1.8 \mathrm{~Tb} / \mathrm{s}$ WDM system implemented with sixteen channels, each of $112 \mathrm{~Gb} / \mathrm{s}$ SB-CAP or MB-CAPscheme,is performedand simulated using OptiSystem version 14.0. The sixteenCW lasers are combined with channel spacing of $100 \mathrm{GHz}$. Thechannel wavelength of the WDM are chosen according to spectral grids for WDM applications that are recommended by International Telecommunication Union (ITU). Table 1 listed the frequencies of the optical carrier (channel frequency) for two operating bands,Cband and O-band, for channel-spacing of $100 \mathrm{GHz}$.

The bandwidth of each channel of the WDM system is $70 \mathrm{GHz}$ when $\mathrm{M}=16$ (CAP-16). The multiplexer and de-multiplexer filters are designed using 6th order bandpass Bessel filter having bandwidth of [0.75 times the bit rate $(\mathrm{GHz})]$. The orthogonal SRRC shaping filters at the transmitter and the matched filters at the 
receiver are located at different center frequencies with roll-off factor of 0.2. The BER performance of the MB-CAP scheme is tested for $\mathrm{B} 2 \mathrm{~B}$ case and after transmission distance of $1 \mathrm{~km}$. The results of MB-CAP are compared with that of the SB-CAP. The target of the investigation is to compare the performance of MBCAP with SB-CAP at the value of aforementioned channel-spacing. The gained results are summarized by the following subsections. Unless otherwise stated, the parameters of the simulated system are as given in Table 2.

\subsection{Performance of the System at Channel-spacing of $100 \mathrm{GHz}$}

First, the results are obtained using CW laser, each has a power PT $=0 \mathrm{dBm}$, operating at C-band or Oband for B2B and after transmission distance of $1 \mathrm{~km}$ for channel spacing of $100 \mathrm{GHz}$. The critical factor in the operation is the bandwidth of the RF power spectral density for the MB-CAP and SB-CAP signals, which equals to $33.9 \mathrm{GHz}$. This bandwidth is divided into four subbands for MB-CAPas shown in Figure 3 which is obtained for C-band operation. The optical power spectral density of the

Table.1 Channel frequencies at 100Ghz channel-spacing

\begin{tabular}{|c|c|c|}
\hline $\begin{array}{l}\text { Channel } \\
\text { number }\end{array}$ & $\begin{array}{c}\text { Channel } \\
\text { frequency at } \\
\text { C-band (THz) }\end{array}$ & $\begin{array}{c}\text { Channel } \\
\text { frequency at } \\
\text { O-band ( } \mathrm{THz} \text { ) }\end{array}$ \\
\hline 1 & 193.1 & 228.3 \\
\hline 2 & 193.2 & 228.4 \\
\hline 3 & 193.3 & 228.5 \\
\hline 4 & 193.4 & 228.6 \\
\hline 5 & 193.5 & 228.7 \\
\hline 6 & 193.6 & 228.8 \\
\hline 7 & 193.7 & 228.9 \\
\hline 8 & 193.8 & 229.1 \\
\hline 9 & 193.9 & 229.2 \\
\hline 10 & 194.1 & 229.3 \\
\hline 11 & 194.2 & 229.4 \\
\hline 12 & 194.3 & 229.5 \\
\hline 13 & 194.4 & 229.6 \\
\hline 14 & 194.5 & 229.7 \\
\hline 15 & 194.6 & 229.8 \\
\hline
\end{tabular}


Table 2. Parameters values of the simulated system.

\begin{tabular}{|c|c|c|}
\hline Component & Property & Value \\
\hline \multirow{2}{*}{$\begin{array}{l}\text { NRZ Pulse } \\
\text { Generator }\end{array}$} & Rise time & 0.25 bit \\
\hline & Fall time & 0.25 bit \\
\hline \multirow[t]{3}{*}{ CW laser } & Line width & $50 \mathrm{MHz}$ \\
\hline & operation & C-band or O-band \\
\hline & Power & $0 \mathrm{dBm}$ \\
\hline \multirow[t]{4}{*}{ Optical fiber link } & Length & $1 \mathrm{~km}$ \\
\hline & Attenuation & $\begin{array}{c}0.2 \text { dB/ } \mathrm{km} @ \mathrm{C}- \\
\text { band } \\
0.4 \mathrm{~dB} / \mathrm{km} @ \mathrm{O}- \\
\text { band }\end{array}$ \\
\hline & Dispersion & $\begin{array}{c}16.75 \mathrm{ps} / \mathrm{nm} / \mathrm{km} @ \\
\text { C-band } \\
0.01 \mathrm{ps} / \mathrm{nm} / \mathrm{km} @ \\
\text { O-band }\end{array}$ \\
\hline & Dispersion slope & $\begin{array}{c}0.075 \mathrm{ps} /\left(\mathrm{nm}^{2} \mathrm{~km}\right) \\
\text { @ C-band } \\
0.09 \mathrm{ps} / /\left(\mathrm{nm}^{2} \mathrm{~km}\right) \\
\text { @ O-band }\end{array}$ \\
\hline \multirow[t]{2}{*}{ PIN PD } & Responsivity & $1 \mathrm{~A} / \mathrm{W}$ \\
\hline & $\begin{array}{l}\text { Power spectral } \\
\text { density of the } \\
\text { thermal noise }\end{array}$ & $\begin{array}{c}331.92 \times 10^{-24} \\
W / H z\end{array}$ \\
\hline
\end{tabular}

multiplexed 16 channels' signals is given in Figure 4. The dispersion between the received adjacent channels is obviously appeared at the de-multiplexed optical power spectral density of the first, ninth and sixteenth channels as illustrated in Figure 5. At the receiver side, the fiber optics nonlinearity and dispersion effects along the fiber link influence the constellation diagram at the QAM demodulation output. The rotation in the received electrical signal constellation for the $1^{\text {st }}, 9^{\text {th }}$, and $16^{\text {th }}$ channels is evident in Figure 6. Figure 7a clarifies the signal constellation at the output of transmitter SRRC shaping filters. While Figure $7 \mathrm{~b}, \mathrm{c}$ and $\mathrm{d}$ are the signal constellation at the output of DSP package after off-line signal processing, Note that the signal points are equally-spaced for the first, ninth and sixteenth but, are totally shifted to the above in the $(x-y)$ plane of the constellation for the first channel.

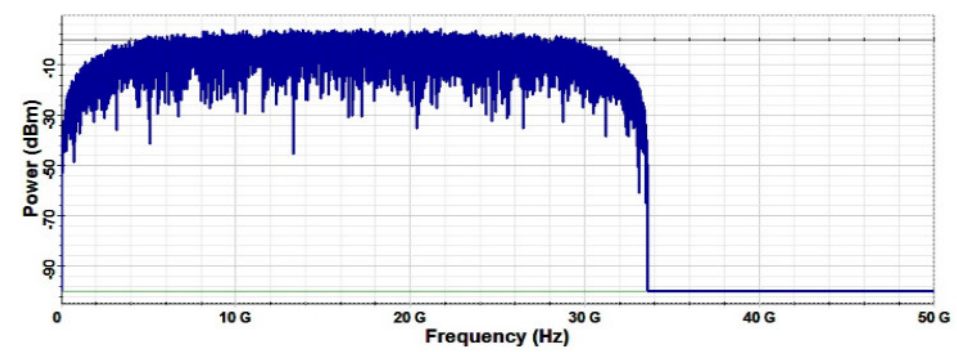

(a) 


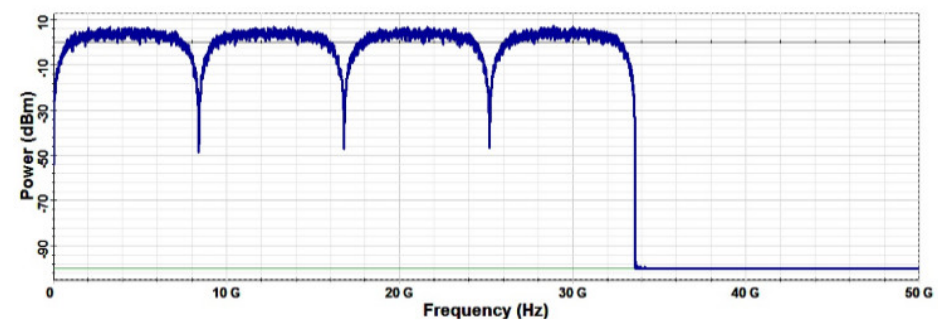

(b)

Figure. 3 RF power spectral density at PT = $0 \mathrm{dBm}, \mathrm{L}=1 \mathrm{~km}$, and C-band operation for (a) SB-CAP signal (b) MB-CAP signal.

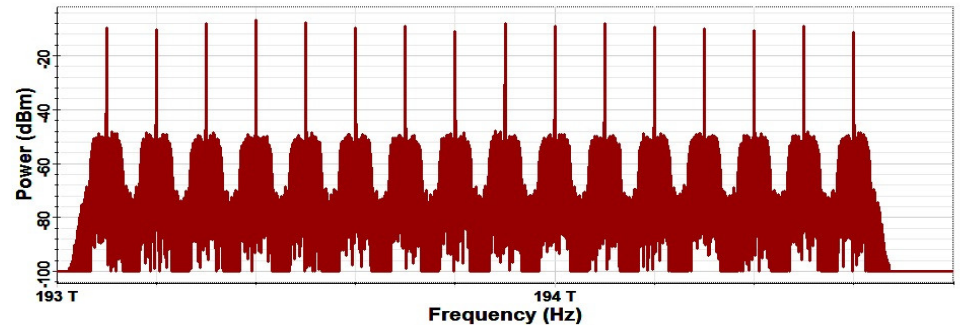

Figure. 4 Optical power spectral density at the output of the WDM multiplexerat $P_{T}=0 \mathrm{dBm}, \mathrm{L}=1 \mathrm{~km}, \mathrm{C}-$ band operation

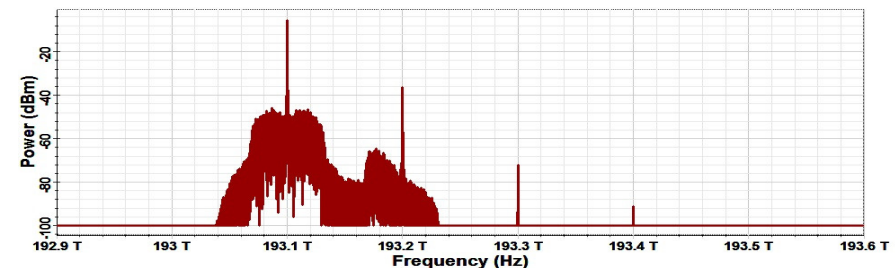

(a)

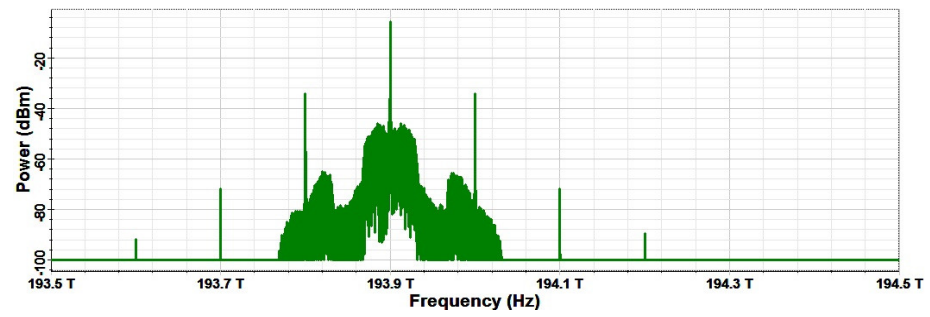

(b)

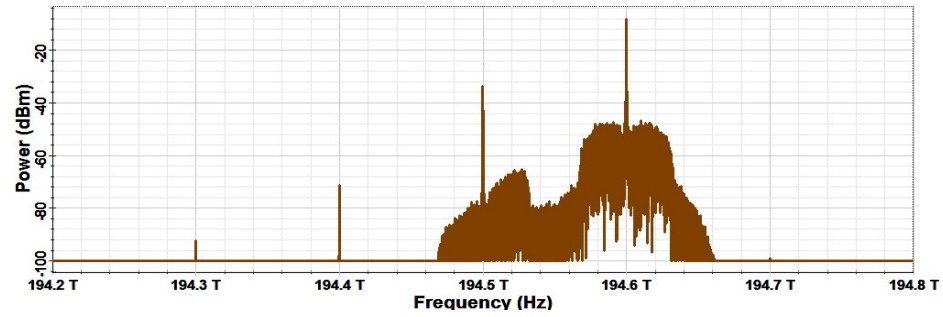

(c)

Figure. 5 Optical power spectral density at the output of the WDM de-multiplexer at $P_{T}=0 \mathrm{dBm}, \mathrm{L}=1 \mathrm{~km}$, and C-band operation for the (a) $1^{\text {st }}$ channel (b) $9^{\text {th }}$ channel (c) $16^{\text {th }}$ channel 
Majidah H. Majeed and Raad S. Fyath; Toward $1.8 \mathrm{~Tb} / \mathrm{s}$ CAP Schemes for Short Reach Optical Communication Systems, Transactions on Networks and Communications, Volume 5 No. 1, February (2017); pp: 39-52

For $\mathrm{B} 2 \mathrm{~B}$ transmission and $1 \mathrm{~km}$ transmission distance along fiber link operating at $\mathrm{C}$-band operation, the BER performance of the SB-CAP system is approximately the same, as shown in Figure 8. The MB-CAP has higher BER compared with SB-CAP counterpart, the case is different for higher values of CW laser power $(-3.5$ to 4$) \mathrm{dBm}$. It is also deduced that the $16^{\text {th }}$ channel has the best performance among other channels due to the absence of the effect of cross phase modulation phenomena whose effect is clearly appears in the BER performance of the $9^{\text {th }}$ channel. As consequence of this phenomena, the overlapping between the previous and the following channels' signals makes the ninth channel 's BER to be of the highest value. The $1^{\text {st }}$ channel's BER curve is in between that of the $9^{\text {th }}$ channel and that of the $16^{\text {th }}$ channel for the singleband as shown in Figure 8. For MB-CAP system, the BER of the $1^{\text {st }}$ channel is approximately the mirror image of that of the $16^{\text {th }}$ channel as shown in Figure 9.

The simulation and the calculation are repeated for WDM system operating at the O-band and the results are presented in Figures 10 and 11. The power improvement for B2B of MB-CAP and SB-CAP compared with $1 \mathrm{~km}$ transmission distance with respect to the $1^{\text {st }}$ channel is $0.6 \mathrm{dBm}$ and $0.5 \mathrm{dBm}$, respectively.

\subsection{Summary of the Results}

This section summarizes the main results for $1.8 \mathrm{~Tb} / \mathrm{s}$ SB-CAP and MB-CAP WDM systems operating with $100 \mathrm{GHz}$ channel-spacing at either C-band or O-band. The results are given for CAP-16 and SRRC filters having 0.2 roll-off factor. The maximum allowable distance that could be reached by $1.8 \mathrm{~Tb} / \mathrm{s} \mathrm{SB}-\mathrm{CAP}-16$ and MB-CAP-16 systems at channel-spacing of $100 \mathrm{GHz}$ are listed in Table 3. The results are obtained for BER of $10^{-3}$ and $P_{T}=0 \mathrm{dBm}$.

Table 4 compares the performance of single-band and multiband CAP-16 systems for channel-spacing $\Delta f$ $=100$. Two operating bands, namely $\mathrm{C}$ and $\mathrm{O}$ are considered.

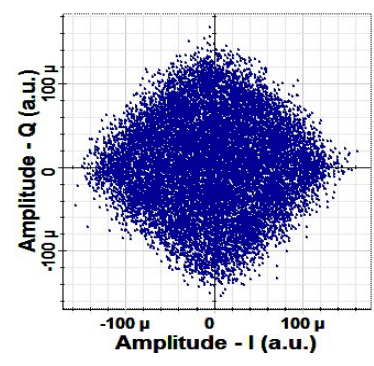

(a)

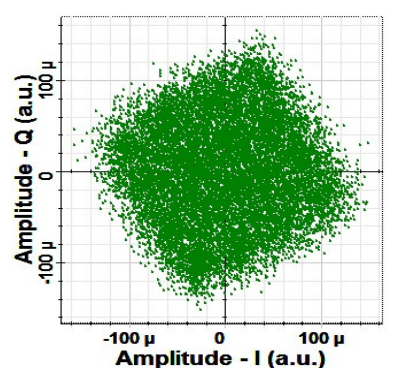

(b)

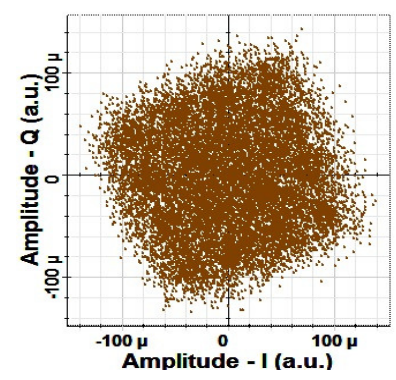

(c)

Figure. 6 Signal constellation at the output of receiver matched filter for the (a) 1st channel (b) 9th channel, (c)16th channel at PT $=0 \mathrm{dBm}, \mathrm{L}=1 \mathrm{~km}$, and C-band operation. 


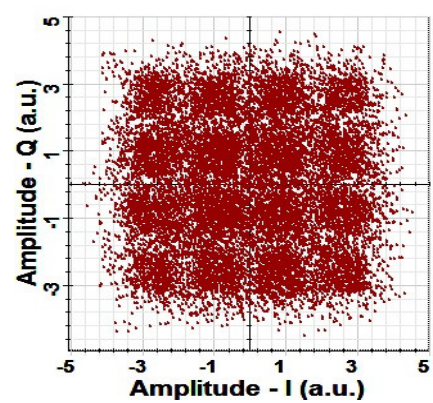

(a)

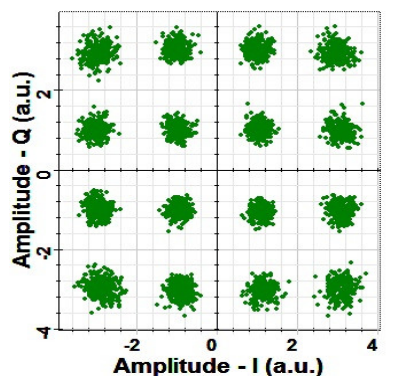

(c)

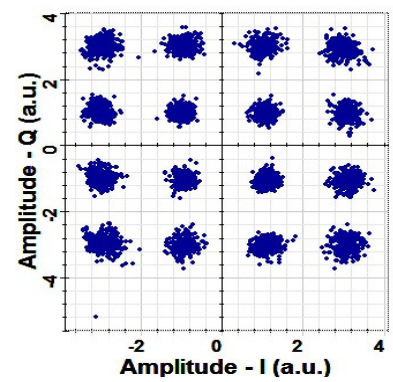

(b)

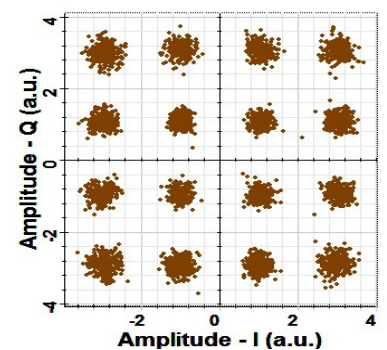

(d)

Figure. 7 (a) Constellation of at the output of SRRC shaping filter constellation after off-line processing at the receiver for the (b)1st channel, (c) 9th channel (d) 16th channel at PT $=0 \mathrm{dBm}, \mathrm{L}=1 \mathrm{~km}$, and C-bandoperation.

\section{Conclusions}

A $1.8 \mathrm{~Tb} / \mathrm{s}$ WDM consisting of sixteen $112 \mathrm{~Gb} / \mathrm{s}$ SB-CAP and MB-CAP channels' are proposed for short reach through applications. The system operates at either C-band or O-band with $100 \mathrm{GHz}$ channel spacing. Simulation results have been reported for CAP-16 signaling while the detection is achieved using hybrid CAP-16/QAM-16 scheme. The results reveal that maximum allowable distance at BER of $10^{-3}$ is $3.45 \mathrm{~km}$ and $2.11 \mathrm{~km}$ for SB-CAP and MB-CAP operating at C-band with $0 \mathrm{~dB}$ laser power, respectively. These values to be compared with $4.5 \mathrm{~km}$ and $1.8 \mathrm{~km}$, respectively, for O-band operation

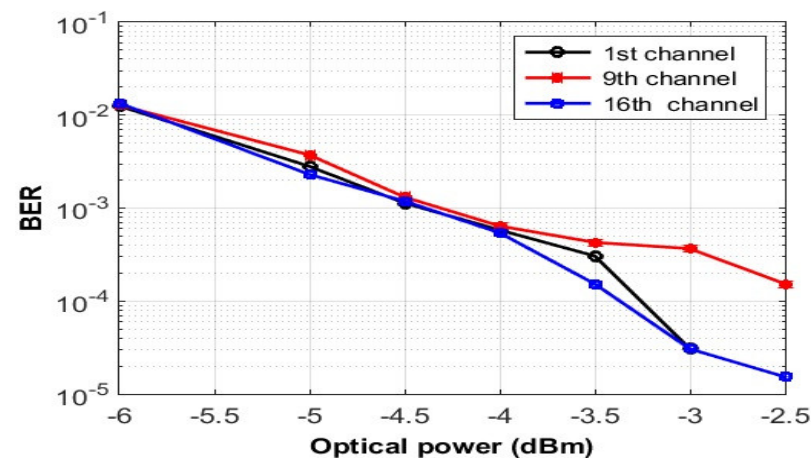

(a)

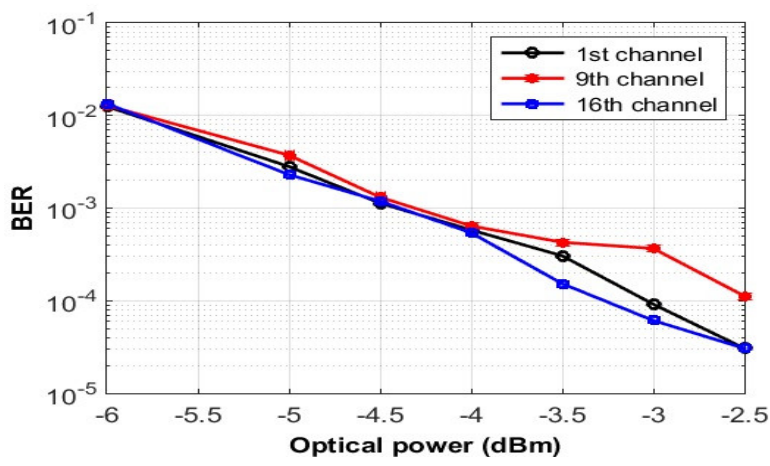

(b)

Figure. 8 System performance of SB-CAP operating at C-band and channel-spacing of $100 \mathrm{GHzfor}$ (a) B2B (b) after $1 \mathrm{~km}$ transmission distance. 


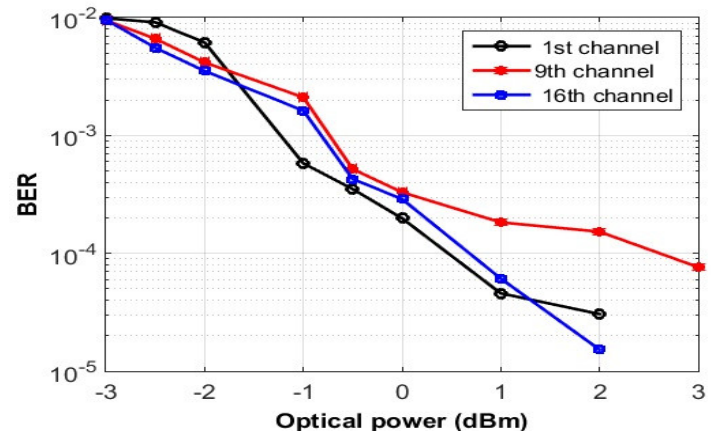

(a)

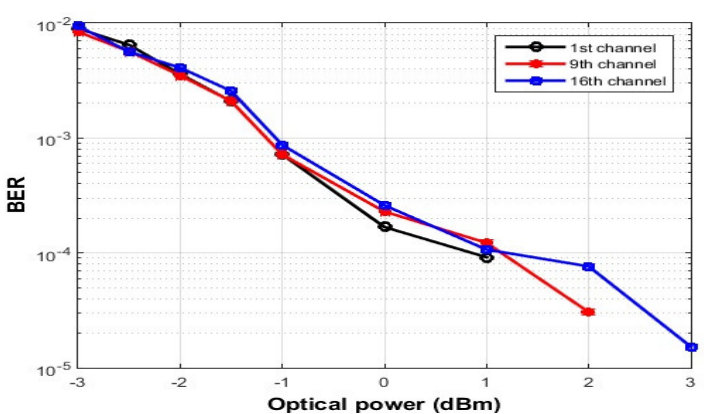

(b)

Figure. 9 System performance of MB-CAP operating at C-band, channel-spacing of 100 GHzfor (a) B2B (b) after $1 \mathrm{~km}$ transmission distance.

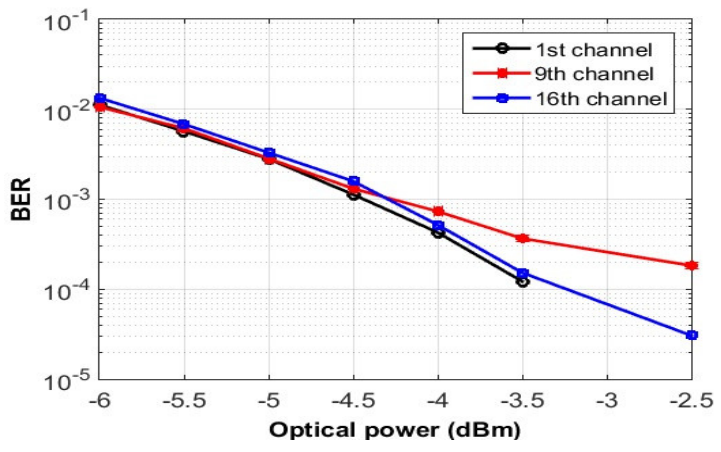

(a)

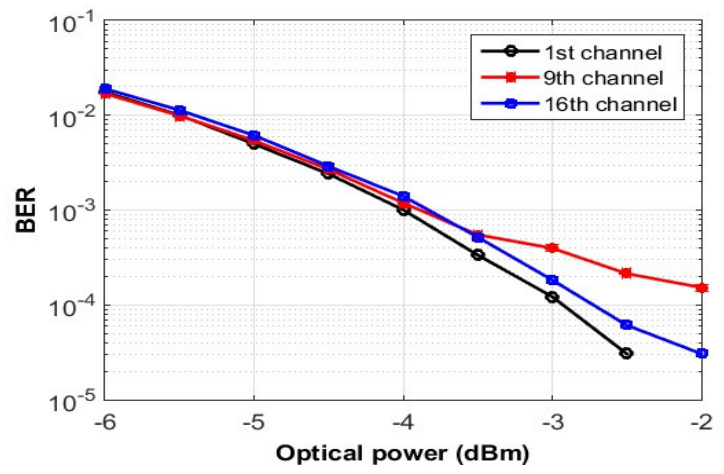

(b)

Figure. 10 System performance of SB- CAP operating at O-band, channel-spacing=100 GHz for (a) B2B (b) after $1 \mathrm{~km}$ transmission distance.

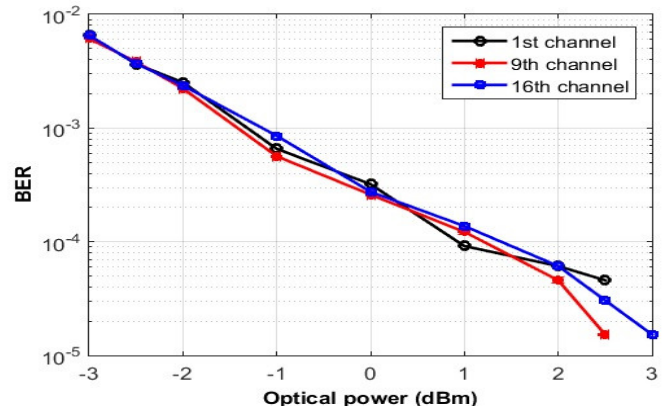

(a)

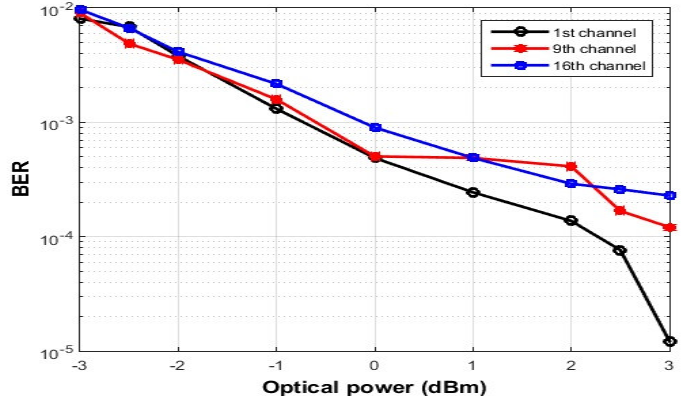

(b)

Figure. 11 System performance of MB-CAP operating at O-band, channel-spacing=100 GHz for (a) B2B (b) after $1 \mathrm{~km}$ transmission distance. 
Table 3. Maximum allowable distance to achieve a BER of $10^{-3}$ for SB-CAP and MB-CAP systems, at channelspacing of $100 \mathrm{GHz}$ and $\mathrm{PT}=0 \mathrm{dBm}$

\begin{tabular}{|c|c|c|c|c|}
\hline \multirow{2}{*}{$\begin{array}{c}\text { Channel } \\
\text { Number }\end{array}$} & \multicolumn{4}{|c|}{$\begin{array}{c}\text { Maximum allowable distance to achieve a BER } \\
\left.\text { of } \mathbf{1 0}^{\mathbf{- 3}} \mathbf{( k m}\right)\end{array}$} \\
\cline { 2 - 5 } & \multicolumn{2}{|c|}{ C-band } & \multicolumn{2}{c|}{ O-band } \\
\cline { 2 - 5 } & SB-CAP & MB-CAP & SB-CAP & MB-CAP \\
\hline 1 & 3.45 & 2.4 & 5.25 & 1.76 \\
\hline 9 & 3.45 & 2 & 4.5 & 1.8 \\
\hline 16 & 3.625 & 2.475 & 5 & 1.8 \\
\hline
\end{tabular}

Table 4. Performance comparison of SB-CAP and MB-CAP at channel-spacing of $100 \mathrm{GHz}$ and PT=0 dBm

\begin{tabular}{|c|c|c|c|c|}
\hline \multirow{2}{*}{ Property } & \multicolumn{2}{|c|}{ C-band } & \multicolumn{2}{|c|}{ O-band } \\
\hline & SB-CAP & MB-CAP & SB-CAP & MB-CAP \\
\hline BER at $1 \mathrm{~km}$ & $\begin{array}{c}\text { The lowest BER is } \\
\text { obtained at } \\
-2.5 \mathrm{dBmas} \\
\text { follows } \\
1^{\text {st }} \text { channel, } \\
\text { BER }=4.521 \times 10^{-5} \\
9^{\text {th }} \text { channel } \\
\text { BER }=1.012 \times 10^{-5} \\
16^{\text {th }} \text { channel, } \\
\text { BER }=4.521 \times 10^{-5}\end{array}$ & $\begin{array}{c}\text { The lowest BER } \\
\text { obtained at } \\
3 \mathrm{dBm} \text { as follows } \\
1^{\text {st }} \text { channel, } \\
\text { BER }=0 \\
9^{\text {th }} \text { channel } \\
\text { BER }=0 \\
16^{\text {th }} \text { channel, } \\
\text { BER }=3.052 \times 10^{-5}\end{array}$ & $\begin{array}{l}\text { While in O-band The } \\
\text { BER is better than that } \\
\text { of C-band it decrease } \\
\text { considerably even if for } \\
\text { higher laser power, } \\
\text { there is } 0.5 \mathrm{dBm} \text { laser } \\
\text { power improvement for } \\
\text { B2B compared to } 1 \mathrm{~km} \\
\text { fiber link } \\
1^{\text {st }} \text { channel, BER=0 } \\
9^{\text {th }} \text { channel } \\
\text { BER }=3.052 \times 10^{-5} \\
16^{\text {th }} \text { channel, } \\
\text { BER }=4.251 \times 10^{-5}\end{array}$ & $\begin{array}{l}\text { The shape of BER is } \\
\text { better than that of C- } \\
\text { band there is } 0.6 \mathrm{dBm} \\
\text { laser power } \\
\text { improvement for B2B } \\
\text { compared to } 1 \mathrm{~km} \text { fiber } \\
\text { link } \\
1^{\text {st }} \text { channel, } \\
\text { BER }=1.521 \times 10^{-5} \\
9^{\text {th }} \text { channel } \\
\text { BER }=1.521 \times 4 \\
16^{\text {th }} \text { channel, } \\
\text { BER=3.521 } \times 10^{-5}\end{array}$ \\
\hline $\begin{array}{c}\text { Maximum } \\
\text { allowable } \\
\text { distance }(\mathrm{km})\end{array}$ & 3.45 & 2.11 & 4.50 & 1.80 \\
\hline
\end{tabular}




\section{Table 4. Continued}

\begin{tabular}{|c|c|c|c|c|}
\hline \multirow[t]{2}{*}{ Property } & \multicolumn{2}{|c|}{ C-band } & \multicolumn{2}{|c|}{ O-band } \\
\hline & SB-CAP & MB-CAP & SB-CAP & MB-CAP \\
\hline $\begin{array}{l}\text { Operation of } \\
\text { the system }\end{array}$ & $\begin{array}{c}\text { There is } \\
\text { interference } \\
\text { between the } 16 \\
\text { subbands, but it is } \\
\text { lessthan that of } \\
\text { MB CAP-16 }\end{array}$ & $\begin{array}{l}\text { The effect of } 64 \\
\text { subbandsincreas } \\
\text { s the interference } \\
\text { between the in- } \\
\text { phase and } \\
\text { quadrature } \\
\text { channels, in } \\
\text { addition to the } \\
\text { effect of the } \\
\text { attenuation and } \\
\text { CD of the fiber } \\
\text { link }\end{array}$ & $\begin{array}{l}\text { Better than that of } \mathrm{C}- \\
\text { band }\end{array}$ & $\begin{array}{l}\text { Same as in MB-CAP in } \\
\text { the C-band, despite the } \\
\text { zero dispersion of this } \\
\text { band. }\end{array}$ \\
\hline
\end{tabular}

\section{REFERENCES}

[1] Tao. L,Ji. Y, Liu. J,Pak.A, Lau. T,Chi.N, and Lu. C, "Advanced Modulation Formats for Short Reach Optical Communication Systems,"IEEE Network, pp. 6-13, Nov/Dec 2013.

[2] Wei. J,Cunningham.D, Penty. R, and White.I, "Study of 100 Gigabit Ethernet Using Carrierless Amplitude/phase Modulation and Optical OFDM," Journal of Light wave Technology, vol. 31, no. 9, May 2013, pp. 1367-1373.

[3] Kikuchi. N,Hirai. R, and Fukui. T, "Practical Implementation of $100 \mathrm{~Gb} / \mathrm{s} /$ Lambda Optical Short-Reach Transceiver with Nyquist PAM4 Signaling Using Elect absorptive Modulated Laser (EML)," 2015.

[4] Xu.X, Zhou. E,Liu. G,Zuo.T, Zhong. Q,Zhang. L,Bao. Y, Zhang. X, Li.J, and Li, Z, “Advanced Modulation Formats for $400 \mathrm{~Gb} / \mathrm{s}$ Short-Reach Optical inter-connection," Optics Express, vol. 23, no. 1Jan 12 2015, pp. 492-500.

[5] Chagnon. M, Osman, M, Poulin.M, Latrasse. C,Frederic.J, Painchaud. Y, paquet.C, Lessard. S, and Plant.D, "Experimental Study of $112 \mathrm{~Gb} / \mathrm{s}$ Short Reach Transmission Employing PAM Format and SiP Intensity Modulator at $1.3 \mu \mathrm{m}, "$ Optics Express, vol. 22, no. 17, August 25, 2014.

[6] Tao. L,Wang.Y, Xiao. J, and Chi. N, "Enhanced Performance of $400 \mathrm{~Gb} / \mathrm{s}$ DML-Based CAP System Using Optical Filtering Technique for Short Reach Communication," Optics Express, vol. 22, no.24, December 1 2014.

[7] Zhong. K,Chen.W, Sui.Q, Man. J, Lau.A, Lu. C, and Zeng.L, "Experimental Demonstration of $500 \mathrm{Gbit} / \mathrm{s}$ Short Reach Transmission Employing PAM4 Signal and Direct Detection with 25 Gbps Device," Optical Society of America, 2015. 
[8] Alves. T, and A. Cartaxo. A, "Performance Assessment of XPM-Limited Direct-Detection Short-Reach DSB OFDM Optical Systems," J. Opt. Communication. Network, vol, 7, no. 8/ AUGUST 2015, 736-747.

[9] Xie. C, Dong. P,Randel.S, Pilori.Winze.P, Spiga. S, Kogel.B, Neumeyr.C, and Amann. M, "Single -VCSEL 100 Gb/s Short Reach System Using Discrete Multi-Tone Modulation and Direct Detection," Optical Society of America, 2015

[10] Li. F, L. X,Chen. L,. Xia.Y, Ge. C, and Chen.Y, “High-Level QAM OFDM System Using DML for Low-Cost Short Reach Optical Communications," IEEE Photonics Technology Letter, vol. 26, no. 9, MAY 1 2014, pp.941944.

[11] Tang, J.He.J, Li.D, Chen. M, andChen. L, “64/128-QAM Half-Cycle Subcarrier Modulation for Short Reach Optical Communications, " IEEE Photonics Technology Litters vol. 27, no. 1, February2014, pp 284-287.

[12] Chen.M, He. J, andChen.L, "Real- Time Demonstration of 1024-QAm OFDM Transmitter in Short-Reach IMDD Systems," IEEE Photonics Technology Letter, vol. 27, no. 8, APRILL, 15, 2015, pp. 824-827.

[13] Wei. J,Ingham.J, Cunningham. D, Penty. R, and White. I, "Performance and Power Dissipation Comparison s Between 28 Gb/s NRZ, PAM, and Optical OFDM Systems for Data Communication Applications, " Journal of Lightwave Technology, vlo. 30, no. 20, October 15 2012, pp. 3273-3280.

[14] Wu, F. Lin. C, Wei. C, Chen, Z, Chen. H, Huang, and Chi.S, " Performance Comparison of OFDM Signal and CAP Signal Over High Capacity RGB-LED-Based WDM Visible Light Communication," IEEE Photonics Journal, vol. 5, no. 4, August 2013.

[15] Amiralizadeh.S, Yrkani.A, and Rusch.L, "Discrete Multi-Tone Transmission with Optimized QAM Constellations for Shot Reach Optical Communications," journal of Lightwave Technology, vol. xx, no, xx, 2016.

[16] Pilori.D, Fludger.C, and Gaudino.R, "Comparing DMT Variants in Medium-Reach 100 G Optically Amplified Systems,"IEEE Journal of Lightwave Technology, vol. 34, no, 14, July. 15 2016, pp. 3389-3399.

[17] Wang. Y, Yu.J, Chi. N, and Chang.G, "Experimental Demonstration of 120-Gb/s Nyquist PAM8-SCFDE for Short-Reach Optical Communication," IEEE Photonics Journal, vol. 7 no. 4, August 2015.

[18] Rodes. R, Mueller, M. Li.B, Estaran.J, Jensen. J,Gruendl.T, Ortsiefer.M, Neumeyr.C, rosskopf. J,Larsen. K,Amann. M, and Monroy. I, "High-Speed 1550 nm VCEL Data Transmission Link Emplying 25 GBd 4-PAM Modulation and Hard Decision Forward Error Correction," Journal of Lightwave Technology, vol. 31, no. 4 February 15 2013, pp. 689-695.

[19] Osman. M Chagnon. M, Poulin. M,Lessard.S, and plant. D, "224-Gb/s 10-km Transmission of PDM PAM-4 at $1.3 \mu \mathrm{m}$ Using a Single Intensity- Modulated Laser and a Direct-Detection MIMO DSP-Based Receiver," Journal of Lightwave Technology, vol. 33, no. 7, APRIL 1, 2015, pp. 1417-1424

[20] Dong. Z,Yu.J, and Lu. J, “Bandwidth-Efficient WDM-CAP-PON Using Digital Hilbert Single-Sideband Modulation," IEEE Photonics Journal, vol, 7, no.5, October 2015. 
Majidah H. Majeed and Raad S. Fyath; Toward $1.8 \mathrm{~Tb} / \mathrm{s}$ CAP Schemes for Short Reach Optical Communication Systems, Transactions on Networks and Communications, Volume 5 No. 1, February (2017); pp: 39-52

[21] Tao. L,Wang. Y,Gao.Y, Pak. A,Lau. T,Chi.N, and Lu. C, “Experimental Demonstration of 10 Gb/s Multi-level Carrier-less Amplitude and Phase Modulation for Short Range Optical Communication Systems," Optics Express, vol. 21, no.5 2013.

[22] Sun. L, Du. J, and He. Z, "Multiband 3-Dimentional Carrierless Amplitude Phase Modulation for Short Reach Optical Communications," Lightwave Technology, 2015.

[23] Wei, J,David. Q,Cunningham. G,Penty. R, and White.I, "100- Gb\s Hybrid Multiband CAP\QAM Signal Transmission Over a Single Wavelength," Journal of Light wave Technology, vol. 33, no. 2, January, 15, 2015, pp. 415-423.

[24] Tao. L, Wang.Y, Gao. Y, Pak. A,Lao.T, Chi. N, and Lu. C, “40 Gb/s CAP32 System With DD-LMS Equalizer for Short Reach Optical Transmissions," IEEE Photonics Technology Letters, vol. 25, no. 23, December 1, 2013, pp. 2346-2349.

[25] Tao.L, Wang. Y, Gao.Y, and Chi. N, "High Order CAP System Using DML for Short Reach Optical Communications," ," IEEE Photonics Technology Letters, vol. 26, no. 13, JULY 1, 2014, pp. 1348-1351

[26] He. J,Dong. H, Deng, R, Li. T, and Chen. L, "Enhanced Performance of CAP System Using Overlap Frequency-Domain Equalization Scheme," IEEE Photonics Journal, vol. 8, no. 2, April 2016.

[27] Zhang.J, Yu. J,Li.F, Chi. N,Dong. Z, and Li.X, “11×25×9.3 Gb/s WDM -CAP -PON Based on Optical SingleSide Band Multi-level Multiband Carrierless Amplitude and Phase Modulation with Direct Detection," Optics Express, vol. 21, no. 16, August 12, 2013.

[28] Olmedo. M,Zuo. T, Jensen. J,Zhong.Q, Xu. X,Monroy. I, “Multiband Carrierless Amplitude Phase Modulation for High Capacity Optical Data Links," Lightwave Technology, vol. 32, no. 4, Feb. 2014 , pp. 798-804

[29] Wei.J, Ingham. J,Cheng. Q, Cunningham. D,Penty. R, and White.I, "Experimental Demonstration of Optical Data Links Using a Hybrid CAP/QAM Modulation Scheme" Optics Letters voL 39, no. 6 / March 15, 2014, pp. 1402-1405. 